\title{
Characterizing the Self-System over Time in Adolescence: Internal Structure and Associations with Internalizing Symptoms
}

\author{
Seth J. Schwartz • Theo A. Klimstra • \\ Koen Luyckx • William W. Hale III • \\ Wim H. J. Meeus
}

Received: 23 December 2011/ Accepted: 20 February 2012/Published online: 9 March 2012

(C) Springer Science+Business Media, LLC 2012

\begin{abstract}
The longitudinal effects among self and identity processes, and between these processes and internalizing symptoms, are not well understood. As a result, the present study was designed to ascertain the over-time effects among identity commitment, reconsideration of commitments, and self-concept clarity, as well as to map the interplay of these self and identity processes with anxiety and depressive symptoms in early adolescence. A sample of 923 Dutch adolescents (mean age 12.4 years at Time 1; 49.3\% female) participated at each of five annual assessments. Multivariate growth curve and cross-lagged panel models indicated that the association between self-concept clarity and commitment was bidirectional, that reconsideration occurs based on problems or dissatisfaction with self-concept clarity and with identity commitments, and that self-concept clarity (but not commitment or reconsideration) temporally precedes depressive and anxiety symptoms. Results are discussed in terms of the structure of the self-system and its associations with internalizing symptoms.
\end{abstract}

T. A. Klimstra and K. Luyckx are FWO Postdoctoral Researchers.

S. J. Schwartz $(\square)$

Department of Epidemiology and Public Health,

Leonard M. Miller School of Medicine, University of Miami, 1425 N.W. 10th Avenue, Suite 321, Miami, FL 33136, USA

e-mail: SSchwartz@med.miami.edu

T. A. Klimstra $\cdot$ K. Luyckx

School Psychology and Adolescent Development, Faculty of Psychology, Catholic University of Leuven, Leuven, Belgium

W. W. Hale III · W. H. J. Meeus

Research Centre on Adolescent Development,

Utrecht University, Utrecht, The Netherlands
Keywords Self-concept clarity · Personal identity · Depressive symptoms · Anxiety symptoms .

Early adolescence

\section{Introduction}

"Self" and "identity" are among the most commonly used terms in the social sciences (Brubaker and Cooper 2000; Leary 2004), but it is often unclear what these terms mean. These terms have both been used in many different ways within various social-science subfields, to the extent that it has become necessary for each writer to define what she or he means by these terms. Depending on how it is defined, for example, "identity" might refer to the constellation of one's goals, values, and beliefs, to feelings of solidarity with groups to which one belongs, or to roles that one plays within the larger social structure (Vignoles et al. 2011). Certain meanings of "self" and "identity" are likely to be complementary-such as self-concept and personal identity (Roeser et al. 2006) — and might be grouped together under the heading of a larger self-system (Vignoles et al. 2011). Specifically, from a developmental perspective, personal identity in early adolescence represents the interplay of certainty and uncertainty (Crocetti et al. 2008b; Schwartz et al. 2005; cf. Erikson's 1968, concepts of identity coherence and confusion). Self-concept represents the person's view of her/himself, as well as the extent to which the various components of this self-view (i.e., academic competence, competence with peers, physical attractiveness) fit together into a coherent structure (Harter 1999). Schwartz et al. (2011b) have provided empirical evidence that personal identity certainty and the clarity of one's self-concept are closely related to one another. As a result, self and identity processes are conceptually similar, 
and research is needed to map the interrelationships of these processes with one another.

Personal Identity: Erikson, Marcia, and Extensions of Marcia's Identity Status Model

From a developmental perspective, the term "identity" generally refers to personal identity-that is, the specific set of goals, plans, and beliefs that one has established or has internalized from significant others (Bosma and Kunnen 2001). Developmentally oriented personal identity theory and research traces its origins to the pioneering work of Erikson (1950) and Marcia (1966). Erikson proposed that the development of personal identity takes place largely during adolescence and the transition to adulthood, after the arrival of formal operational thought but before the individual has settled into permanent adult roles. He characterized the development of personal identity as a tension between synthesis and confusion, where individuals with greater degrees of synthesis are likely to be emotionally stable and mature, but where individuals with greater degrees of confusion are likely to be more anxious, depressed, and prone to engaging in health-compromising behaviors (Luyckx et al. 2008c; Schwartz et al. 2009c, 2011a).

Marcia (1966) recast Erikson's identity stage in terms of two key processes-exploration and commitment. Exploration refers to sorting through various potential alternatives to which one might commit, whereas commitment refers to a decision to adhere to one or more sets of personal goals, values, ideals, and beliefs. In Marcia's view, a process of exploring and then committing represents the most adaptive and effective way to develop a sense of personal identity (Kroger and Marcia 2011). However, exploration does not necessarily lead to the enactment of commitments, and commitments can be enacted without prior exploration (Marcia 1980, 1993; Meeus et al. 2010).

The field of personal identity has advanced considerably in the past 10 years, most prominently through the generation of new identity models that build on and extend Marcia's framework. Indeed, Erikson's conception of personal identity extends well beyond exploration and commitment (e.g., Côté and Levine 2002). The certaintyuncertainty (confusion-synthesis) dynamic postulated by Erikson (1968) implies that identity is developed by attaching oneself to a set of ideals, adhering to these ideals for as long as they resonate with the person and provide a stable foundation for one's choices and activities, and revising or dismissing these ideals when they no longer provide such a stable foundation. Identity development is therefore a dynamic process and does not end when commitments are enacted (Kroger and Marcia 2011). The goal of identity development, from an Eriksonian perspective, is to construct a sense of self that is positive, is internally consistent, and provides the individual with a positive selfimage, a set of roles within society and in relation to other people, and an intangible sense of "capital" that can be used to gain entry into desired social positions (e.g., peer groups, universities, jobs; Côté and Levine 2002). Such a sense of self is essential also because it anchors the person with a given set of social roles and protects against aimlessness associated with symptoms of anxiety, depression, conduct problems, and antisocial behavior (cf. Crocetti et al. 2008b; Luyckx et al. 2006; Schwartz et al. 2011a).

Among the newer identity models is the dynamic model proposed by Meeus and colleagues (Crocetti et al. 2008a, b; Meeus et al. 2010). This model, along with other newer identity models (e.g., Luyckx et al. 2008a), frames commitment as a process rather than an event-that is, as both enacting commitments and of integrating them into the person's overall sense of self. Importantly, newer models of identity may be particularly applicable to younger adolescents, for whom identity development may involve increases and decreases in uncertainty rather than active, consciously determined, in-breadth exploration (cf. Schwartz et al. 2009a).

Specifically, Crocetti et al. (2008b) refer to "reconsideration of commitment." Reconsideration is characterized by a desire to discard or change one's current commitments, and it is associated with hesitation, uncertainty, and confusion regarding how to proceed with one's identity development (Crocetti et al. 2008b). Like exploration in breadth, reconsideration has been positively associated with depressive and anxiety symptoms, both cross-sectionally (Crocetti et al. 2008b) and longitudinally (Schwartz et al. 2011b).

Within the Meeus et al. model, commitment and reconsideration therefore represent a certainty-uncertainty dynamic (Klimstra et al. 2010c; Schwartz et al. 2011b), similar to Erikson's (1950) dynamic between identity synthesis and confusion. Enacting and maintaining commitments is associated with decreases in confusion and distress (Luyckx et al. 2008b), whereas discarding —or preparing to discard - one's commitments is associated with increases in confusion and distress (Schwartz et al. 2009b). One would hypothesize, then, that commitment and reconsideration would exert opposing effects on symptoms of distress such as anxiety and depression. In early adolescence, the dynamic between certainty and uncertainty is more tenable than conscious, intentional exploration and commitmentas we explain in the next section.

\section{Identity Development in Early Adolescence}

The identity status model was developed to examine identity development in late adolescence and the transition to adulthood (Kroger and Marcia 2011). Accordingly, the 
majority of studies on identity status have used late adolescent, emerging adult, or adult samples (Schwartz 2005). The measures used to assess identity status have likewise been designed for these age groups-particularly in terms of the content domains surveyed (e.g., politics, religion, career, gender roles) and the assumption that commitments are best assessed in terms of conscious decisions to embrace specific goals, values, and beliefs (Waterman 1999). Not surprisingly, studies on early adolescents using these measures have suggested that this age group is largely diffused or foreclosed (i.e., lacking identity commitments or having enacted them without exploring other options; Meeus 1996).

Although more recent identity status-based research has begun to include younger adolescents (Kroger and Marcia 2011), we still know far more about how identity is consolidated in late adolescence and emerging adulthood than about how identity development begins in early adolescence (Schwartz 2005). Studying identity in early adolescence requires more "general" measures and the use of content domains that are relevant to this age group. Using such approaches, a number of studies, using different samples and measures (e.g., Klimstra et al. 2010b; Schwartz et al. 2009a, 2011b), have detected identity development activity in young adolescents. This activity, however, is quite different than what has been observed in older populations. Where change does occur, it is more likely to appear as decreases in confusion and uncertainty than by increases in certainty.

Despite this observation that early adolescence is characterized primarily by changes in uncertainty or confusion, research has suggested that, when measured in age-appropriate ways, these early signs of identity work may be linked with successful identity development in later adolescence and during the transition to adulthood (Meeus et al. 2010). Further, longitudinal studies indicate that the overall pace of identity development is similar between early and late adolescence (Meeus et al. 1999, 2010).

Indeed, the certainty-uncertainty dynamic as posited by Meeus and colleagues (Crocetti et al. 2008b; Klimstra et al. 2010c) parallels Erikson's (1950) dynamic between identity coherence and confusion. Schwartz et al. (e.g. 2009a, 2005) have used Eriksonian indices of identity coherence and confusion to detect identity activity in early adolescents. In both of these lines of research, indices of uncertainty and confusion have been linked with symptoms of anxiety, depression, and other problematic outcomes.

\section{Self, Self-Concept, and Self-Concept Clarity}

In our work on self, we focus here on self-concept, which has been defined as an appraisal of one's skills, abilities, or competence-either overall or within specific domains such as athletics, academics, and social relationships (Bouchey and Harter 2005). Indeed, one's self-concept in a specific domain, such as academics, is often directly predictive of one's performance in that domain (Guay et al. 2004). General self-concept-which focuses on one's overall description of one's skills and competence-has been found to relate inversely to internalizing symptoms (Robles-Piña et al. 2008).

However, Campbell (1990) has cautioned against assessing self-concept in an overly general sense. She argues that such general operationalizations of self-concept overlap greatly with self-esteem. Indeed, Harter (1999) has found much the same pattern, where her scale that was intended to assess global self-concept is essentially a measure of self-esteem. As a result, we focus here on what Campbell et al. (1996) have termed self-concept clarity. Self-concept clarity refers to the extent to which one's view of oneself is internally consistent, stable, and confident. Clearly, this definition overlaps with self-esteem (Campbell et al. 2003), but self-concept clarity adds the dimension of consistency and integration across the various aspects of one's self (e.g., academic and social competence, physical attractiveness). In prior work, self-concept clarity has been found to be strongly and negatively associated with internalizing problems (Campbell et al. 2003; Stopa et al. 2010). Further, self-concept clarity has emerged as an especially strong predictor of internalizing symptoms, over and above other self-related constructs (Constantino et al. 2006).

A notable limitation of extant research on self-concept clarity is that no published longitudinal studies have been conducted on this construct. A search of the PsycInfo literature database from 1990 (when the term was first used) through December 2011, seeking records with the term "self-concept clarity" in the title, abstract, or keywords yielded 71 records, all of which were cross-sectional or experimental studies. The functions of self-concept clarity over time are therefore in need of study. The definition of self-concept clarity - a coherent, positive, and firm sense of who one is - suggests that it might be more of a trait than a developmental process, but longitudinal research is needed to examine this issue. Erikson's (1968) notions of identity coherence and confusion are conceptually similar to selfconcept clarity. According to Erikson (1950), identity synthesis is characterized by consistency and integration among one's various roles and commitments-suggesting that making commitments is associated with, but does not guarantee, a synthesized sense of identity and a clear sense of self. Further, Schwartz et al. (2009a) found developmental change in identity confusion over time-suggesting that self-concept clarity might also represent a developmental construct. 
Identity and Self-Concept Clarity: Overlapping or Distinct?

There is not only a need for longitudinal studies on selfconcept clarity, but also a need for longitudinal research on personal identity. Meeus (2011) reviewed longitudinal personal identity research conducted between 2000 and 2010, and found only a small handful of such studies. Moreover, many of the studies were conducted on adults, and only a few used adolescent samples. Of those that did utilize adolescent samples, none examined the directionality of associations between personal identity processes and psychosocial functioning, and none used both self-concept and identity processes as predictors of other constructs. To understand the functions of identity (cf. Serafini and Adams 2002), we must map its contributions to adjustment over time-as well as to examine the ways in which identity might be predicted by earlier levels of psychosocial adjustment. Schwartz et al. (2011b) found that anxiety and depressive symptoms were predicted by, but not predictive of, daily variations in reconsideration. However, the directionality of effects between self/identity and adjustment variables has not been explored on a longer-term basis (e.g., over a series of yearly assessments).

Additionally, there is a need to focus on internalizing symptoms as a correlate of identity development in adolescence (Schwartz 2005). Indeed, self-esteem, well-being, and other positive outcomes traditionally have been used as outcome variables in personal identity research (Berzonsky 2003; Meeus et al. 1999; Waterman 2004, 2007). Only in the last several years have internalizing problems been more widely examined as correlates or outcomes of identity processes or statuses (e.g., Crocetti et al. 2008b; Luyckx et al. 2008b, c, d). There is a clear need for more research-especially longitudinal research-in this direction. Such work would help the personal identity literature to "catch up" with the self-concept literature, where there is a large database of research relating self-concept to both well-being (e.g., Harter 1999; Locke 2006; Slutzky and Simpkins 2009) and internalizing symptoms (e.g., Dishman et al. 2006; Heath and Brown 1999; Montague et al. 2008; Robles-Piña et al. 2008). Moreover, there is evidence that the trajectory of internalizing symptoms in adolescence can be associated with risky behaviors in early adulthood (Wickrama and Wickrama 2010)—suggesting that identifying mechanisms that can protect against the development of depressive and anxiety symptoms in adolescence is critical.

Extant literature suggests that both identity commitments (e.g., Luyckx et al. 2006; Smits et al. 2010) and selfconcept clarity (e.g., Campbell et al. 2003; Stopa et al. 2010) are inversely associated with internalizing symptoms and positively associated with well-being. Moreover, there is some evidence that identity commitments and self-concept clarity are positively predictive of one another across short periods of time (i.e., from 1 day to the next; Schwartz et al. 2011b). This seems to suggest that these two constructs may be part of a larger self-system. However, the extent to which self-concept clarity and identity processes (e.g., commitment and reconsideration) work together to influence - and are influenced by-indices of psychosocial adjustment across adolescence has not been studied in the published literature. If we assume that the "self-system" includes both choices that are enacted and reconsidered and the sense of self that is developed as a result, this opens up an opportunity to understand and articulate how the various components of the self-system predict internalizing problems. Certainty and uncertainty may only be part of the picture-the coherence and organization of one's self may also be important in protecting against internalizing symptoms in adolescence.

If the self-system hypothesis, as we are advancing it here, suggests that commitments may help to create a synthesized and coherent sense of self, one may assume that self-concept clarity largely may explain the beneficial effects of commitment on internalizing symptoms. Put differently, once self-concept clarity is accounted for, does commitment predict any additional variability in internalizing symptoms? This question is important both empirically and clinically: if self-concept clarity is the mechanism that is most closely linked with depressive and anxiety symptoms, then intervention efforts should be targeted toward this variable. However, to the extent to which commitment predicts depressive and anxiety symptoms beyond the effects of self-concept clarity, intervening to facilitate the development of commitments-or at least to promote a sense of certainty in the adolescent's lifemay be important.

The role of reconsideration is also essential to consider. Given that reconsideration has been found to be linked with depressive and anxiety symptoms (Crocetti et al. 2008b), what is its role within the self-system? What processes are predictive of reconsideration-under what circumstances does it occur, and what consequences does it have for psychosocial functioning? Within the Meeus et al. model, reconsideration is the vehicle through which identity is revised. Grotevant (1987) suggested that identity exploration would be most likely to occur when the person's current commitments and sense of self were no longer satisfactory or functional. If one accepts that commitments help to create a clear and coherent sense of self, Grotevant's proposition would suggest that reconsideration would be expected to occur when self-concept clarity is low. Such reconsideration likely would continue until satisfactory commitments-those that facilitate self-concept clarity-were enacted. Reconsideration therefore appears 
to be the process through which identity commitments are revised.

Because anxiety and depressive symptoms have been among the most commonly studied correlates of the selfsystem (e.g., Campbell et al. 2003; Constantino et al. 2006; Crocetti et al. 2008b; Luyckx et al. 2008a) and are used as outcomes in the present study, it is important to review the normative developmental course of these symptoms in early and middle adolescence. For example, Generalized Anxiety Disorder symptoms, which commonly occur in adolescents from the general community, tend to be largely stable during early and middle adolescence before increasing somewhat (especially for girls) in late adolescence and emerging adulthood (Hale et al. 2008; van Oort et al. 2009). Similarly, depressive symptoms tend to be low and stable for most adolescents, with highly stressed adolescents experiencing increases in depressive symptoms during the course of adolescence (Garber et al. 2002). Both anxiety and depressive symptoms appear to be endorsed more strongly by girls than by boys (Hankin and Abramson 2001; van Oort et al. 2009). It is therefore plausible that identity processes may explain variations in internalizing symptoms between adolescents-and the present study was designed to examine this possibility.

\section{The Present Study}

In the present study, we adopt an integrative approach that addresses all of the issues that we have reviewed and raised above. We examined both correlated changes (through multivariate growth curve modeling) and direction of effects (through cross-lagged panel modeling). Our two primary objectives were (a) to further our understanding of the self-system by mapping the longitudinal associations among self-concept clarity, commitment, and reconsideration; and (b) to ascertain associations between these three components of the self-system and two indicators of internalizing problems (depressive and anxiety symptoms). Specifically, how does self-concept clarity relate to commitment and reconsideration over time, and how do these three components of the self-system relate to adolescent depressive and anxiety symptoms over time?

We advanced one hypothesis regarding the stability of the self-system over time, and two hypotheses regarding the interrelationship of constructs within the self-system and the relationships between self-system variables and internalizing symptoms. Our first hypothesis was that all of the self-system variables (self-concept clarity, commitment, and reconsideration) would become more highly stable over time, reflecting a more strongly organized selfsystem over the course of early and middle adolescence.

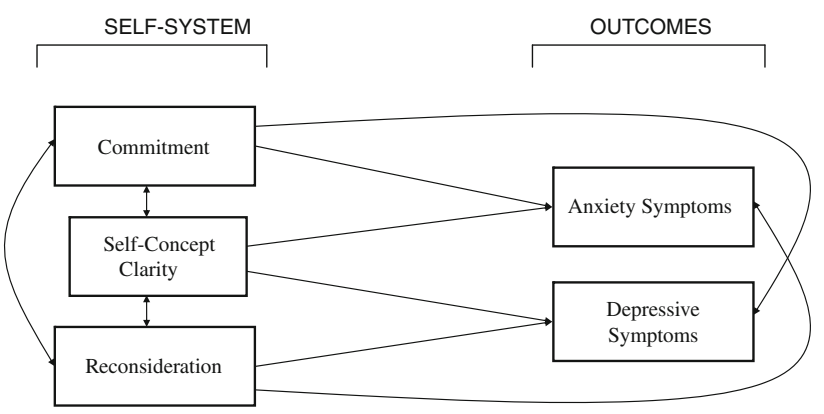

Fig. 1 Hypothesized network of associations among study variables

Given positive associations between commitment and identity synthesis (Schwartz 2007) and between exploration and identity confusion (Schwartz et al. 2009b) found in past research, our second hypothesis was that commitment would positively associate with self-concept clarity, and that reconsideration would negatively associate with selfconcept clarity, over time. That is, we expected that, within growth curve models, intercepts and slopes for commitment and self-concept clarity would positively interrelate; and intercepts and slopes for self-concept clarity and reconsideration would negatively interrelate.

Finally, our third hypothesis was that intercepts and slopes for self-concept clarity and commitment would negatively relate to intercepts and slopes for anxiety and depressive symptoms, but that associations between growth parameters for reconsideration and internalizing symptoms would be positive. In sum, we anticipated that the associations between self-concept clarity and identity would be bidirectional, but that associations between the self-system and internalizing symptoms would be largely unidirectional (cf. Schwartz et al. 2011b). Figure 1 presents these hypotheses in graphical form.

\section{Method}

\section{Participants}

For the present study, we used data from an ongoing longitudinal research project on Conflict and Management of Relationships (CONAMORE; Meeus et al. 2004). The longitudinal sample consisted of 923 early to middle adolescents who were 12.4 years of age on average $(\mathrm{SD}=.59)$ at Time 1 , including 468 boys $(50.7 \%$ of the sample) and 455 girls (49.3\%). Because adolescents were assessed during five annual measurement waves, a total age range from 12 to 16 years was available.

Missing values were estimated using full-information maximum likelihood (FIML) in Mplus release 6.0 (Muthén and Muthén 2007). Across waves, a maximum of $5.9 \%$ of data were missing. Little's (1988) Missing Completely at 
Random test, conducted on the item-level data at all five timepoints, revealed a normed $\chi^{2}\left(\chi^{2} / d f\right)$ of $0.65\left(\chi^{2}\right.$ of $30,690.50$ with $47,359 d f$ ), which was not statistically significant and indicates good correspondence between sample scores with and without estimation of missing values.

\section{Procedure}

Participating adolescents were recruited from various high schools in the Province of Utrecht in the Netherlands. Schools were selected randomly from among those within the province, and adolescents were selected randomly from the Grade 7 rosters within each of the target schools. Participants and their parents received an invitation letter, describing the research project and goals, and explaining that they could decline participation if they so chose. More than $99 \%$ of the students who were approached decided to participate. All participants signed an informed consent form prior to participating in the study. Each year, annual assessments were conducted at the participants' high schools. The measures analyzed for the present study were a subset of those administered at each annual assessment. Participants completed their assessments using paper and pencil, and responses were entered into computerized data files at a later time. Verbal and written instructions were offered to help participants complete the measures, and confidentiality of responses was guaranteed. Each adolescent received $€ 10$ (approximately US \$14) for each wave in which she or he participated.

\section{Measures}

\section{Self-Concept Clarity}

Self-concept clarity was measured using the Self-Concept Clarity Scale (Campbell et al. 1996). The SCC consists of 12 items, each of which is responded to using a five-point Likert scale ranging from 1 (strongly disagree) to 5 (strongly agree). All but two items are reverse-coded. A sample item is "My beliefs about myself often conflict with one another". Reliability was adequate at each timepoint, with Cronbach's alphas ranging from .82 to .88 .

\section{Identity Commitment and Reconsideration}

Identity processes were assessed in domains of education and best friend. Education is one of the most central domains in the lives of adolescents (Porfeli and Skorikov 2010), and friendships are especially important in early and middle adolescence (Branje et al. 2007). We assessed commitment and reconsideration using the UtrechtManagement of Identity Commitments Scale (U-MICS;
Crocetti et al. 2008b), a self-report measure based on the earlier Utrecht-Groningen Identity Development Scale (Meeus 1996). Each item is responded to using a five-point Likert-scale, with responses ranging from 1 (completely untrue) to 5 (completely true). In total, across the two domains, 10 items measure commitment, and 6 items reconsideration. Sample items are: "My education/best friend gives me certainty in life" (commitment) and "I often think it would be better to try and find a different education/best friend" (reconsideration). Items reflecting a sense of certainty, rather than asking about deliberate enactment of commitments, were used because young adolescents are more likely to seek certainty than to make deliberate commitments (e.g., Schwartz et al. 2005). It is worth noting, however, that correlations of the U-MICS commitment subscale with adjustment indices are similar in direction to those found with more traditional commitment measures. Validity and reliability of U-MICS scores have been established for boys and girls, early and middle adolescents, and Dutch and ethnic minority youths (Crocetti et al. 2008a, b). In the present sample, Cronbach's alpha estimates ranged from .86 to .92 for commitment, and from .86 to .89 for reconsideration.

\section{Anxiety Symptoms}

The Screen for Child Anxiety Related Emotional Disorders (SCARED) was used to measure adolescent anxiety symptoms. The SCARED is a self-report questionnaire used to measure symptoms of anxiety disorders in children and adolescents. It has been shown to provide reliable and valid scores (Birmaher et al. 1997; Muris et al. 1999; Muris and Steerneman 2001), and its factor structure has consistently been replicated across gender and across age groups (Hale et al. 2005). The SCARED consists of 38 items, and the first four subscales: panic disorder symptoms (13 items), social anxiety symptoms (4 items), separation anxiety symptoms ( 8 items), and generalized anxiety symptoms (9 items) are related to DSM-IV-TR anxiety disorder symptoms; whereas the fifth subscale, school phobia symptoms (4 items), although it is an commonly occurring anxiety in children and adolescents, is not classified in the DSM-IV-TR. A recent meta-analytic study (Hale et al. 2011) has demonstrated that the total SCARED score is a valid and reliable measure of anxiety symptoms in adolescents. As a result, in the present study, the composite anxiety score was used. Sample items include "When frightened, it is hard to breathe", "I don't like to be with people I don't know", "I get scared when I sleep away from home", "I worry about others not liking me", and "I get headaches or stomach aches when I am at school". The items are scored on a 3-point scale, including "hardly ever", "sometimes", and "often". In the current study, Cronbach's alphas ranged from .96 to .98 across waves. 


\section{Depressive Symptoms}

Depressive symptoms were measured with the Children's Depression Inventory (CDI; Kovacs 1985), a self-report questionnaire aimed at screening (subclinical) depressive symptomatology in children and adolescents. This scale has demonstrated convergent and discriminant validity, good internal consistency and adequate test-retest reliability in previous studies (Craighead et al. 1998; Hodges 1990). The CDI consists of 27 items (e.g., "I'm sad all the time"). The items were scored on a 3-point scale, ranging from 1 (false) to 3 (very true). Reliability of the CDI was high across waves-Cronbach's alphas ranged from .90 to .93 .

\section{Results}

\section{Data Analytic Plan}

The data analytic plan for the present study consisted of three general steps. The first step was to present descriptive statistics (across timepoints) and bivariate correlations (at baseline) for all study variables. The second and third steps focus on ascertaining the extent to which self-concept clarity, commitment, and reconsideration represent components of the self-system, as well as the extent to which these self and identity variables are related to anxiety and depressive symptoms over time. The second step was to examine change over time in concept clarity, commitment, and reconsideration. We did this in two ways-rank-order stability analyses and multivariate growth curve modeling. To ascertain rank-order stability, we examined the Pearson correlation of each construct with itself at consecutive timepoints. This allowed us to ascertain how stable the self, identity, and internalizing constructs in our study were over time in early and middle adolescence. Moreover, if rankorder stability correlations for self-construct clarity, commitment, and reconsideration increase over time, this would suggest that the self-system becomes more stable and consistent over time during early and middle adolescence. In terms of growth modeling, we estimated a multivariate latent growth model for self-concept clarity, commitment, and reconsideration. This model allowed us to ascertain the extent to which changes in each of the self/ identity constructs over time would be associated with changes in each of the others.

We also estimated a multivariate growth curve model including anxiety and depressive symptoms as well as the self/identity constructs. We estimated separate growth models within the self-system and for the associations of the self-system with internalizing because maximum likelihood estimation is an iterative process, and the addition of new variables can cause fluctuations in model parameters. The model including internalizing symptoms allowed us to explore the associations between growth parameters for self-concept clarity, commitment, and reconsideration with growth parameters for anxiety and depressive symptomsand to test the hypothesis that changes in self-concept clarity and commitment would be associated negatively, and changes in reconsideration associated positively, with changes in symptoms of anxiety and depression.

The third step of analysis was to examine directionality in these associations by estimating cross-lagged panel models. These models would permit us to examine the extent to which each dimension of the self-system would predict (and be predicted by) the others across time. We estimated two cross-lagged models-one with only selfconcept clarity, commitment, and reconsideration (to ascertain the directionality among the self and identity constructs) - and a second between the self/identity variables and anxiety and depressive symptoms. In the second model, we only explored the cross-lagged associations between self/anxiety and internalizing symptoms, given that the associations among the self/identity variables are reported from the first cross-lagged model. Two separate panel models were required because the addition of new predictors (in this case depression and anxiety) would change the regression coefficients for the self-system components predicting one another (Keith 2006).

\section{Descriptive Statistics}

Means and standard deviations for all study variables, at each timepoint, are presented in Table 1. This table suggests that the means for each study construct are largely stable across time (although reconsideration decreases somewhat at the last two timepoints). Table 2 presents bivariate correlations among study variables at each timepoint. Self-concept clarity was most strongly related to symptoms of both anxiety and depression at each timepoint; Pearson-Filon $t$ tests comparing the correlations of anxiety and depressive symptoms with self-concept clarity versus the corresponding correlations with commitment and reconsideration were all highly significant $(t$ values ranged from 2.98 to 5.83 , all $p \mathrm{~s}<.01)$.

\section{Rank-Order Stability}

We next examined rank-order stability-the extent to which an individual's place within the sample, in terms of the magnitude of her/his score, is consistent across time. We examined differences in these rank-order stability coefficients between the first and last time lags using both statistical significance and effect size. Cohen (1988) recommends using the $z$ test for independent correlation 
Table 1 Descriptive statistics for study variables by timepoint ${ }^{\mathrm{a}}$

\begin{tabular}{llllll}
\hline Timepoint & $\begin{array}{l}\text { Self-concept clarity } \\
\text { M }\end{array}$ & $\begin{array}{l}\text { Commitment }^{\mathrm{b}} \\
\mathrm{M}(\mathrm{SD})\end{array}$ & $\begin{array}{l}\text { Reconsideration }^{\mathrm{c}} \\
\mathrm{M}(\mathrm{SD})\end{array}$ & $\begin{array}{l}\text { Depressive symptoms }^{\mathrm{c}} \\
\text { M (SD) }\end{array}$ & $\begin{array}{l}\text { Anxiety symptoms }^{\mathrm{c}} \\
\text { M (SD) }\end{array}$ \\
\hline Time 1 & $3.63(0.78)$ & $3.65(0.72)$ & $2.03(0.91)$ & $1.16(0.26)$ & $1.32(0.29)$ \\
Time 2 & $3.61(0.78)$ & $3.75(0.61)$ & $2.03(0.89)$ & $1.18(0.23)$ & $1.32(0.28)$ \\
Time 3 & $3.65(0.75)$ & $3.74(0.61)$ & $2.05(0.89)$ & $1.18(0.23)$ & $1.29(0.27)$ \\
Time 4 & $3.67(0.79)$ & $3.75(0.61)$ & $1.91(0.82)$ & $1.19(0.24)$ & $1.28(0.25)$ \\
Time 5 & $3.74(0.78)$ & $3.75(0.57)$ & $1.84(0.73)$ & $1.18(0.21)$ & $1.25(0.24)$ \\
\hline
\end{tabular}

${ }^{a}$ Values in the table are item means

b Variable was measured on a 1-5 scale

c Variable was measured on a 1-3 scale

Table 2 Within-time correlations among study variables by timepoint

\begin{tabular}{|c|c|c|c|c|c|c|}
\hline \multirow[t]{2}{*}{$\begin{array}{l}\text { Table } 2 \text { Within-time } \\
\text { correlations among study } \\
\text { variables by timepoint }\end{array}$} & Variable & Self-concept clarity & Commitment & Reconsideration & $\begin{array}{l}\text { Depressive } \\
\text { symptoms }\end{array}$ & $\begin{array}{l}\text { Anxiety } \\
\text { symptoms }\end{array}$ \\
\hline & \multicolumn{6}{|c|}{ Self-concept clarity } \\
\hline & Time 1 & - & $.11 * * *$ & $-.10 * *$ & $-.34 * * *$ & $-.32 * * *$ \\
\hline & Time 2 & & $.19 * * *$ & $-.19 * * *$ & $-.45 * * *$ & $-.40 * * *$ \\
\hline & Time 3 & & $.19 * * *$ & $-.12 * * *$ & $-.47 * * *$ & $-.44 * * *$ \\
\hline & Time 4 & & $.26 * * *$ & $-.18 * * *$ & $-.53 * * *$ & $-.52 * * *$ \\
\hline & Time 5 & & $.20 * * *$ & $-.24 * * *$ & $-.57 * * *$ & $-.56 * * *$ \\
\hline & \multicolumn{6}{|c|}{ Commitment } \\
\hline & Time 1 & & - & $.13 * * *$ & $-.12 * * *$ & $-.07 *$ \\
\hline & Time 2 & & & -.01 & $-.18 * * *$ & $-.07 *$ \\
\hline & Time 3 & & & .00 & $-.18 * * *$ & $-.12 * * *$ \\
\hline & Time 4 & & & $-.08 *$ & $-.24 * * *$ & $-.16^{* * *}$ \\
\hline & Time 5 & & & $-.26 * * *$ & $-.24 * * *$ & $-.16^{* * *}$ \\
\hline & \multicolumn{6}{|c|}{ Reconsideration } \\
\hline & Time 1 & & & - & $.16^{* * *}$ & $.19 * * *$ \\
\hline & Time 2 & & & & $.17 * * *$ & $.20 * * *$ \\
\hline & Time 3 & & & & $.11 * *$ & $.20 * * *$ \\
\hline & Time 4 & & & & $.09 * *$ & $.14 * * *$ \\
\hline & Time 5 & & & & $.14 * * *$ & $.17 * * *$ \\
\hline & \multicolumn{6}{|c|}{ Depressive symptoms } \\
\hline & Time 1 & & & & - & $.55 * * *$ \\
\hline & Time 2 & & & & & $.52 * * *$ \\
\hline & Time 3 & & & & & $.64 * * *$ \\
\hline & Time 4 & & & & & $.66 * * *$ \\
\hline & Time 5 & & & & & $.68 * * *$ \\
\hline & \multicolumn{6}{|c|}{ Anxiety symptoms } \\
\hline & Time 1 & & & & & - \\
\hline & Time 2 & & & & & \\
\hline & Time 3 & & & & & \\
\hline & Time 4 & & & & & \\
\hline $\begin{array}{l}* p<.05 ; * * p<.01 \\
* * * p<.001\end{array}$ & Time 5 & & & & & \\
\hline
\end{tabular}

$* p<.05 ; * * p<.01 ;$ $* * * p<.001$ coefficients and the $q$ effect size. The $q$ value is calculated as the difference between the Fisher $Z$ coefficients for the two correlations being compared. A $q$ value of .10 indicates a small difference, a value of .30 indicates a moderate difference, and a value of .50 indicates a large difference (Cohen 1988).

As displayed in Table 3, for all study variables except reconsideration, the correlations between the Time 4 and 
Table 3 Rank-order stability coefficients

$* p<.05 ; * * p<.01$; $* * * p<.001$

Table 4 Intercept and slope terms for study variables

In cases where both the estimate and the standard error are below 1.00 , both numbers are rounded to the third decimal place

$* p<.05 ; * * p<.01$;

$* * * p<.001$

a Standard error is $<0.001$

\begin{tabular}{lllll}
\hline Variable & Time 1-Time 2 & Time 2-Time 3 & Time 3-Time 4 & Time 4-Time 5 \\
\hline Self-concept clarity & $.49 * * *$ & $.56 * * *$ & $.57 * * *$ & $.69 * * *$ \\
Commitment & $.33 * * *$ & $.48^{* * *}$ & $.48^{* * *}$ & $.48^{* * * *}$ \\
Reconsideration & $.43^{* * *}$ & $.51^{* * *}$ & $.48^{* * *}$ & $.45^{* * *}$ \\
Depressive symptoms & $.44 * * *$ & $.49 * * *$ & $.48^{* * *}$ & $.58^{* * *}$ \\
Anxiety symptoms & $.38^{* * *}$ & $.54 * * *$ & $.59 * * *$ & $.67 * * *$ \\
\hline
\end{tabular}

\begin{tabular}{|c|c|c|c|c|}
\hline \multirow[t]{2}{*}{ Variable } & \multicolumn{2}{|l|}{ Mean } & \multicolumn{2}{|l|}{ Variance } \\
\hline & Estimate (SE) & $t$ value & Estimate (SE) & $t$ value \\
\hline \multicolumn{5}{|c|}{ Self-concept clarity } \\
\hline Intercept & $3.57(0.03)$ & $131.01 * * *$ & $0.360(0.035)$ & $10.15 * * *$ \\
\hline Slope & $0.032(0.007)$ & $4.62 * * *$ & $0.021(0.002)$ & $8.46 * * *$ \\
\hline \multicolumn{5}{|c|}{ Commitment } \\
\hline Intercept & $7.35(0.05)$ & $153.40 * * *$ & $0.837(0.127)$ & $6.60 * * *$ \\
\hline Slope & $0.033(0.012)$ & $2.76^{* *}$ & $0.038(0.009)$ & $4.32 * * *$ \\
\hline \multicolumn{5}{|c|}{ Reconsideration } \\
\hline Intercept & $5.77(0.07)$ & $86.88 * * *$ & $1.931(0.249)$ & $7.75^{* * *}$ \\
\hline Slope & $-0.096(0.015)$ & $6.20 * * *$ & $0.053(0.017)$ & $3.10 * *$ \\
\hline \multicolumn{5}{|c|}{ Depressive symptoms } \\
\hline Intercept & $1.17(0.01)$ & $125.08 * * *$ & $0.037(0.005)$ & $7.22 * * *$ \\
\hline Slope & $0.003(0.002)$ & 1.26 & $0.002(0.000)^{\mathrm{a}}$ & $5.92 * * *$ \\
\hline \multicolumn{5}{|c|}{ Anxiety symptoms } \\
\hline Intercept & $1.34(0.01)$ & $134.07 * * *$ & $0.041(0.006)$ & $6.66 * * *$ \\
\hline Slope & $-0.018(0.002)$ & $7.55^{* * *}$ & $0.002(0.000)^{\mathrm{a}}$ & $4.84 * * *$ \\
\hline
\end{tabular}

Time 5 scores were greater than the correlations between the Time 1 and Time 2 scores. All of these differences were statistically significant using the $z$ test for independent correlation coefficients: self-concept clarity, $z=13.38$, $p<.001, q=.31 ;$ commitment, $z=7.73, \quad p<.001$, $q=.18$; depression, $z=8.16, p<.001, q=.19 ;$ and anxiety, $z=17.62, p<.001, q=.41$. Rank-order stability coefficients for reconsideration were not significantly different for the Time 1 -Time 2 versus Time 4-Time 5 intervals, $z=1.06, p=.29, q=.02$.

Multivariate Latent Growth Models

\section{Self-Concept Clarity, Commitment, and Reconsideration}

An examination of the means in Table 1 suggests that the means for each of the study variables either were equivalent or changed only slightly over time. As a result, for selfconcept clarity, commitment, and reconsideration, we parameterized the latent growth curves as consisting only of intercepts and linear slopes (Duncan et al. 1999). In all of the growth models that we report, error terms for the same variable at adjacent timepoints were allowed to correlate.
We used standard structural equation modeling fit indices to evaluate the fit of the multivariate latent growth model to the data. Following Weston and Gore (2006), we report the $\chi^{2}$ test, as well as four additional fit indices (see Kline 2006, for a review of the various fit indices). As incremental fit indices, we report the comparative fit index (CFI) and the non-normed fit index (NNFI); and as absolute fit indices, we report the root mean square error of approximation (RMSEA) and the standardized root mean square residual (SRMR). Following Kline (2006), we consider $\mathrm{CFI} \geq .95, \quad \mathrm{NNFI} \geq .90, \quad \mathrm{RMSEA} \leq .05$, and $\mathrm{SRMR} \leq .06$ as indicative of "good" fit, and CFI $\geq .90$, $\mathrm{NNFI} \geq .85, \mathrm{RMSEA} \leq .08$, and $\mathrm{SRMR} \leq .10$ as indicative of "adequate" fit. The RMSEA also provides a $90 \%$ confidence interval, as well as a "close fit probability" that the RMSEA value is below .05 (Hancock and Freeman 2001). The $\chi^{2}$ test, which tests the null hypothesis of perfect fit to the data, is reported but not interpreted because this null hypothesis is rarely tenable (Davey and Savla 2010).

The self-system latent growth curve model fit the data well, $\chi^{2}(78)=143.16, p<.001 ; \mathrm{CFI}=.98 ; \mathrm{NNFI}=.97$; $\mathrm{RMSEA}=.030(95 \% \mathrm{CI}=.022$ to .038 ; close fit probability $>.99)$; SRMR $=.045$. We therefore proceeded to 
examine both (a) the statistical significance of the means and variances of the growth parameters and (b) interceptintercept and slope-slope correlations across constructs.

\section{Significance of Intercept and Slope Terms}

For self-concept clarity, commitment, reconsideration, and anxiety, the means for the slope terms were all significantly different from zero (see Table 4). The mean slope for depression was not statistically significant. The slope variances for all of the study variables were significant but were close to zero. This was especially true for anxiety and depressive symptoms, for which the variance estimates were both .002 . However, taking the square root of this variance estimate yields a standard deviation of .045. For depression, where the mean slope was .003 , a participant with a slope that was $1 \mathrm{SD}$ above the sample mean would be expected to increase by .048 scale points per time lag, or .192 scale points across the four study time lags. This increase represents almost $10 \%$ of the 2-point scale range (from 1 to 3). In contrast, a participant with a slope that was $1 \mathrm{SD}$ below the sample mean would be expected to decrease by .042 scale points per time lag, or .168 scale points across the four study time lags. Assuming that they had the same Time 1 score, these two fictitious participants would score .360 points ( $18 \%$ of the scale range) apart at Time 5. Further suggesting the presence of at least some significant variability in change rates across participants, intercepts and slopes for the study constructs were reliably correlated - in the hypothesized direction-in every case. These correlations among growth parameters are presented in Table 5 and discussed immediately below.

\section{Correlations Among Growth Parameters}

As detailed in the Plan of Analysis section, we first report correlations among growth parameters for self-concept clarity, commitment, and reconsideration. The self-concept clarity intercept was significantly correlated with the intercepts for commitment, $r=.39, p<.001$; and reconsideration, $r=-.25, p<.001$. The intercepts for commitment and reconsideration were not significantly correlated, $r=-.06, p=.51$. All three slope terms were significantly intercorrelated: self-concept clarity with commitment, $r=.47, p<.001$; self-concept clarity with reconsideration, $r=-.42, p<.001$; and commitment with reconsideration, $r=-.49, p<.01$. As a result, although there was only a modest degree of change over time in these variables, the change trajectories were related to one another.

\section{Self-System and Internalizing}

We next focused on associations between the growth parameters for the self/identity variables and those for anxiety and depressive symptoms. We estimated a multivariate growth curve model and examined the associations among the intercepts and among the slopes (see Table 6). This model provided a good fit to the data, $\chi^{2}$ $(246)=512.18, \quad p<.001 ; \quad$ CFI $=.96 ; \quad$ NNFI $=.95 ;$ RMSEA $=.034(90 \% \mathrm{CI}=.030$ to .038$)$, close fit probability $>.99$; SRMR $=.037$. Growth parameters for selfconcept clarity and commitment were negatively related, and growth parameters for reconsideration were positively related, to corresponding growth parameters for depression and anxiety. As was the case with the within-time correlations reported in Table 2, intercept-intercept and slopeslope correlations were stronger for self-concept clarity with depression and with anxiety than for either of the identity variables with depression and anxiety (see Table 5). Pearson-Filon $t$ tests confirmed these correlation differences as significant, with $t$ values ranging from 6.25 to 12.20 (all $p \mathrm{~s}<.001$ ). Moreover, the absolute value of the slope-slope correlation was significantly stronger between commitment and depression than between reconsideration and depression, Pearson-Filon $t=3.38, p<.001$.
Table 5 Correlations between growth parameters for self/ identity and internalizing variables

\begin{tabular}{|c|c|c|c|c|}
\hline \multirow[t]{2}{*}{ Variable } & \multicolumn{2}{|c|}{ Depressive symptoms } & \multicolumn{2}{|c|}{ Anxiety symptoms } \\
\hline & Intercept & Slope & Intercept & Slope \\
\hline \multicolumn{5}{|c|}{ Self-concept clarity } \\
\hline Intercept & $-.74 * * *$ & $.46 * * *$ & $-.75 * * *$ & $.41 * * *$ \\
\hline Slope & $.31 * * *$ & $-.69 * * *$ & $.27 * * *$ & $-.63 * * *$ \\
\hline \multicolumn{5}{|c|}{ Commitment } \\
\hline Intercept & $-.44 * * *$ & $.35 * * *$ & $-.32 * * *$ & $.30 * * *$ \\
\hline Slope & $.34 * * *$ & $-.54 * * *$ & $.29 * * *$ & $-.46 * * *$ \\
\hline \multicolumn{5}{|c|}{ Reconsideration } \\
\hline Intercept & $.40 * * *$ & $-.40 * * *$ & $.47 * * *$ & $-.42 * * *$ \\
\hline Slope & -.32 & $.49 * *$ & $-.26 *$ & $.45^{* *}$ \\
\hline
\end{tabular}


Table 6 Cross-lagged panel coefficients for self-concept clarity, commitment, and reconsideration

$* p<.05 ; * * p<.01 ;$

$* * * p<.001$

\section{Equivalence Across Gender}

Given gender differences in identity processes (Lewis 2003; Schwartz and Montgomery 2002) and in internalizing symptoms (Hankin and Abramson 2001; van Oort et al. 2009), we evaluated each of the growth curve models for equivalence across gender. These equivalence tests were conducted following recommendations from the invariance testing literature (see Chen 2007; Dimitrov 2010, for reviews). A model with all correlations among growth parameters free to vary across gender was compared to a model with all correlations among growth parameters constrained across gender. The fit of the unconstrained and constrained models were then compared in terms of their $\chi^{2}, \mathrm{CFI}$, and NNFI values. The null hypothesis of model equivalence across gender would be rejected if at least two of the following three criteria were met: $\Delta \chi^{2}$ significant at $p<.05$ (Byrne 2011), $\Delta$ CFI $>.005$ (Chen 2007), and $\Delta C F I>.005$ (Chen 2007). Results indicated that both the self-system model, $\Delta \chi^{2}(12)=16.86, p=.15$; $\Delta \mathrm{CFI}=.001 ; \Delta \mathrm{NNFI}<.001 ;$ and the self-system/internalizing symptoms model, $\Delta \chi^{2}(24)=56.09, p<.001$; $\Delta \mathrm{CFI}=.003 ; \Delta \mathrm{NNFI}=.003$, fit equivalently across gender.

\section{Cross-Lagged Panel Models}

Although correlations between and among growth parameters indicate that constructs change in tandem, these analyses do not provide information regarding the directionality of these associations. As a result, our next step of analysis was to estimate cross-lagged panel models across the five timepoints. As we did with the growth curve models, we estimated these in two steps-one using only self-concept clarity, commitment, and reconsideration to map the longitudinal and directional structure of the self-system; and a second model ascertaining the directionality between the self-system and internalizing symptoms. As is common practice in cross-lagged panel modeling (e.g., Klimstra et al. 2010a), we allowed each construct to correlate with itself at successive timepoints, and we estimated covariances between each pair of constructs at each timepoint.

\section{Self-System Model}

The cross-lagged model including self-concept clarity, commitment, and reconsideration provided a good fit to the data, $\chi^{2}(39)=130.07, p<.001 ; \mathrm{CFI}=.97 ; \mathrm{NNFI}=.92 ;$ $\mathrm{RMSEA}=.050(90 \% \mathrm{CI}=.040$ to .060$)$, close fit probability $=.46 ;$ SRMR $=.039$. To simplify interpretation, within each model we imposed the assumption of stationarity-where each cross-lagged path coefficient was constrained equal across time (e.g., the commitment $\rightarrow$ self-concept clarity path was set equal across the Times 1-2, 2-3, 3-4, and 4-5 intervals). We evaluated the tenability of the stationarity assumption by comparing a model with stationarity imposed against a model with all paths free to vary. We then compared the $\chi^{2}$, CFI, and NNFI values between these two models. The invariance testing literature (see Dimitrov 2010, for a review) suggests that if the stationarity-imposed and unconstrained models provide equivalent fit to the data, then the assumption of stationarity can be retained (cf. Giulietti et al. 2009). The stationarity assumption was evaluated using the same criteria used to test for model equivalence (i.e., the assumption would be rejected if two of three criteria were met: $\Delta \chi^{2}$ significant at $p<.05, \Delta \mathrm{CFI}>.005$, and $\Delta \mathrm{CFI}>.005)$.

Results indicated that the assumption of stationarity could be retained, $\Delta \chi^{2}(18)=28.89, p<.05 ; \Delta \mathrm{CFI}=.001$; $\Delta$ NNFI $<.001$. The model with stationarity imposed fit the data adequately, $\chi^{2}(57)=152.46, p<.001 ; \mathrm{CFI}=.97$; $\mathrm{NNFI}=.94 ; \mathrm{RMSEA}=.043(90 \% \mathrm{CI}=.034$ to .051$)$, close fit probability $=.93 ; \mathrm{SRMR}=.042$. We therefore report and interpret only one set of path coefficients (see Table 6). Findings indicated that commitment predicted selfconcept clarity over time, and that reconsideration was predicted by (but did not significantly predict) self-concept clarity and commitment. However, as is often the case in cross-lagged panel modeling, once the autocorrelation is taken into account, path coefficients for other variables are fairly smallso it is difficult to detect significant differences in pairs of cross-lagged coefficients.

\section{Self-Concept Clarity and Identity with Anxiety and Depressive Symptoms}

We then estimated a cross-lagged panel model across the five timepoints, including self-concept clarity, the identity variables, anxiety, and depression. The model fit the data adequately, $\chi^{2} \quad(173)=783.41, \quad p<.001 ; \quad \mathrm{CFI}=.90$; $\mathrm{NNFI}=.84 ; \mathrm{RMSEA}=.062(90 \% \mathrm{CI}=.057$ to .066$)$; $\mathrm{SRMR}=.093$. Tests of invariance indicated that the 
Table 7 Cross-lagged growth models for self/identity variables with anxiety and depressive symptoms

\begin{tabular}{llllll}
\hline Predictor $($ Time $x)$ & \multicolumn{2}{l}{ Dependent variable $($ Time $x+1)$} \\
\cline { 2 - 5 } Variable & Self-concept clarity & Commitment & Reconsideration & Depressive symptoms & Anxiety symptoms \\
\hline Self-concept clarity & - & $\mathrm{N}^{\mathrm{a}}$ & $\mathrm{N} / \mathrm{A}^{\mathrm{a}}$ & $-.20^{* * *}$ & $-.15^{* * *}$ \\
Commitment & $\mathrm{N} / \mathrm{A}^{\mathrm{a}}$ & - & $\mathrm{N} / \mathrm{A}^{\mathrm{a}}$ & $-.08^{* * *}$ & -.01 \\
Reconsideration & $\mathrm{N} / \mathrm{A}^{\mathrm{a}}$ & $\mathrm{N} / \mathrm{A}^{\mathrm{a}}$ & - & .00 & -.02 \\
Depressive symptoms & $-.07^{* *}$ & $-.07^{* *}$ & .02 & - & $\mathrm{N} / \mathrm{A}^{\mathrm{b}}$ \\
Anxiety symptoms & $-.09^{* * *}$ & .04 & $.06^{*}$ & $\mathrm{~N}^{\mathrm{b}}$ & - \\
\hline
\end{tabular}

$* p<.05 ; * * p<.01 ; * * * p<.001$

a These coefficients are reported in Table 6 for the model including only the self-system variables

b The cross-lagged correlations between depressive and anxiety symptoms were not of interest in the present study

assumption of stationarity could be retained, $\Delta \chi^{2}$ $(44)=3.02, p=.99 ; \Delta \mathrm{CFI}=.003 ; \Delta \mathrm{NNFI}<.001$ (see Table 7). Results indicated that, controlling for earlier levels of commitment and reconsideration, self-concept clarity was negatively predicted by earlier levels of depression, $\beta=$ $-.07, p<.002$; and anxiety, $\beta=-.09, p<.001$. Controlling for earlier levels of self-concept clarity and reconsideration, commitment was negatively predicted by earlier levels of depression, $\beta=-.06, p<.02$. Controlling for earlier levels of self-concept clarity and commitment, reconsideration was predicted by earlier levels of anxiety, $\beta=.06, p<.01$. Depression was negatively predicted by earlier levels of both self-concept clarity, $\beta=-.21, p<.08$; and commitment, $\beta=-.05, p<.01$. Anxiety was negatively predicted only by earlier levels of self-concept clarity, $\beta=-.15, p<.001$.

The effects involving commitment and reconsideration were fairly small, and as a result it was unlikely that these effects would differ significantly from the corresponding effects in the opposite direction. However, the effects of self-concept clarity were somewhat larger. To determine whether self-concept clarity was significantly more predictive of subsequent levels of anxiety and depressive symptoms than anxiety and depressive symptoms were of subsequent levels of self-concept clarity, we compared (a) a model with paths in each direction free to vary against (b) a model with paths in each direction constrained equal. We compared these two models using the same criteria used to evaluate the stationarity assumption. These comparisons indicated that the paths were not equivalent across direction-that is, self-concept clarity was a significantly stronger predictor of anxiety and depressive symptoms than vice versa, $\Delta \chi^{2}(2)=45.14, p<.001 ; \Delta \mathrm{CFI}=.005$; $\Delta \mathrm{NNFI}=.006$. Moreover, the $95 \%$ confidence intervals for the standardized self-concept clarity $\rightarrow$ internalizing (depression, -.243 to -.168 ; anxiety, -.187 to -.120 ) and internalizing $\rightarrow$ self-concept clarity (depression, -.110 to -.035 ; anxiety, -.124 to -.053 ) overlap only very slightly-further suggesting that the cross-lagged path coefficients are significantly different from one another.

\section{Equivalence Across Gender}

As a final step of analysis, we tested both cross-lagged models for equivalence across gender. The self-system model was consistent across gender, $\Delta \chi^{2}(24)=26.40, \quad p=.33$; $\Delta \mathrm{CFI}<.001 ; \quad \Delta \mathrm{NNFI}<.001$; but the self-system/internalizing model evidenced some degree of non-equivalence across gender, $\Delta \chi^{2}(48)=56.00, p=.48 ; \Delta \mathrm{CFI}=.009$; $\Delta \mathrm{NNFI}=.016$. To identify the specific paths responsible for the non-equivalence, we followed a procedure outlined by Byrne (2011). We returned to the unconstrained model and constrained one path at a time to identify which paths met criteria for non-equivalence across gender. However, none of the individual paths were non-equivalent across gender, suggesting that the overall finding of non-equivalence was the result of aggregating small deviations across a large number of comparisons. As a result, we tentatively concluded that the self-system/internalizing panel model was likely consistent across gender.

\section{Discussion}

The literatures on self and identity have been extremely fragmented, so much so that work in each of the various self and identity constructs rarely-if ever-references work on other self and identity constructs (Vignoles et al. 2011). In particular, identity commitments and self-concept clarity are quite similar conceptually, yet the effects of these processes on one another across adolescence rarely have been studied. The combined effects of self and identity processes on anxiety and depressive symptoms in adolescence have remained an open empirical question.

Accordingly, the present study was conducted to explore the structure of the self-system over time, and to ascertain the associations of this self-system with adolescent internalizing symptoms (i.e., depressive and anxiety symptoms) over time. The study was conducted in early to middle adolescence, a time when internalizing symptoms may peak for 
some adolescents (Garber et al. 2002; Wickrama and Wickrama 2010). For each set of longitudinal analyses, we first examined correlated changes and then tested for the directionality of these associations.

At least two important sets of findings emerged from these analyses. First, rank-order stability for self-concept clarity, commitment, and depressive and anxiety symptoms increased significantly between early (age 12) and middle (age 16) adolescence. This suggests that the structure of the self-system-as represented by making commitments and maintaining an integrated and coherent sense of self-appears to become better integrated across adolescence, and that consistency of internalizing symptoms (i.e., whether or not one reports high levels of depressive or anxiety symptoms) increases during the course of adolescence. However, it is noteworthy that reconsideration does not become more consistent across adolescence. This suggests that reconsideration may occur on an "as needed" basis. Our results indicate that reconsideration may be precipitated by a sense of dissatisfaction or comfort with one's sense of self, or by elevated levels of anxiety. Discarding or loosening one's commitments may lead to confusion and disequilibrium (Schwartz et al. 2009 b), and possibly to rumination and worry (Luyckx et al. 2008a). Periods of reconsideration therefore may be uncommon compared to periods of commitment and clarity. Indeed, longitudinal findings have suggested that patterns of identity development-especially patterns of commitment making and maintenance-may be quite consistent over time (Meeus et al. 2010)—suggesting that they may be more "trait-like" than "state-like." In the present study, the stability of commitments and self-concept clarity over time suggests some degree of within-person consistency in these processes. Further, our rank-order stability findings suggest that commitment and self-concept clarity become more stable and "traitlike" over time. Indeed, some adolescents may maintain higher levels of commitment and self-concept clarity over time compared to other adolescents, even notwithstanding temporal fluctuations in the strength of a given adolescent's commitments and in the clarity and coherence of her or his self-concept. On the other hand, reconsideration, to the extent to which it occurs only as needed, may be more of a "statelike" process.

Second, the effects that we observed-although they were fairly modest, as is common in cross-lagged modeling once the autocorrelations have been taken into accountsuggest that commitments may lead to a stable and clear self-concept, and that the presence of commitments and of a clear self-concept may decrease the likelihood of reconsideration. Reconsideration appears to occur only when the self-concept that has been created through one's existing commitments is not coherent or consistent. Lack of a clear or coherent self-concept also appears to lead to the development of high levels of depressive and anxiety symptoms, which might then lead to reconsideration. Because reconsideration does not predict depressive and anxiety symptoms in a cross-lagged manner, but reconsideration is associated with depressive and anxiety symptoms in terms of simultaneous changes (i.e., closely associated intercepts and slopes), depressive and anxiety symptoms appear to occur along with reconsiderationassumedly as a result of a poorly organized self-concept.

Put differently, as long as a young adolescent's current commitments are viewed as functional, and as long as the clarity of her or his self-concept is deemed sufficient, reconsideration is unlikely to occur. This may, to some extent, explain the relatively high stability of the foreclosed identity status (commitments enacted without prior exploration) relative to the other identity statuses in early and middle adolescence (e.g., Meeus et al. 2010). Foreclosed individuals tend to be satisfied with themselves, not to be introspective, and to react defensively to the suggestion that anything is wrong with their lives (Berzonsky and Kinney 2008; Schwartz et al. 2011a). At the other extreme, individuals in identity diffusion-especially variants of diffusion characterized by disorganized and ineffective attempts to explore alternatives and enact commitmentsare likely to engage in reconsideration on a repeated and chronic basis (Crocetti et al. 2008a; cf. Luyckx et al. 2005). Repeated reconsideration, without establishing new commitments, is likely to be linked with depressive and anxiety symptoms (Crocetti et al. 2009). In turn, the lack of enduring commitments has the potential to lead to a fragmented self-concept that may not support enduring or adaptive decision-making.

To the extent that commitments and self-concept clarity are individual-difference variables (i.e., generally higher in some adolescents than others) and may also fluctuate over time within a given adolescent, one might expect that reconsideration occurs when commitments, and subsequently self-concept clarity, fall below levels that are characteristic of, or comfortable for, that adolescent. The self-system is dynamic in that reconsideration (in some cases) may lead to adoption of subsequent commitments (Meeus et al. 2010), commitments have the potential to increase the clarity of the self-concept, and self-concept clarity may protect against further reconsideration and against anxiety and depressive symptoms. It may therefore be this set of systemic relationships, rather than absolute levels of self and identity processes, that appears to underlie the self-system. Levels of self-concept clarity that are comfortable for some adolescents may induce discomfort and reconsideration, as well as heightened levels of depressive and anxiety symptoms, in other adolescents.

Although Marcia (1966) proposed exploration and commitment as referring to late adolescents and college students, it appears that commitment operates in early 
adolescence as well. Indeed, young adolescents likely enter their second decade of life with at least some commitments internalized from parents or other significant adults (Bosma and Kunnen 2001). Although active, purposeful exploration may not begin until later in adolescence or in emerging adulthood (Schwartz et al. in press), commitments in early adolescence may be reconsidered by temporarily suspending or discarding them. The extent to which commitments are suspended or discarded in early adolescence appears to be linked with symptoms of anxiety and depression-and this finding parallels results obtained with Hispanic adolescents in the United States (Schwartz et al. 2005, 2009a) with regard to behavior problems, drug and alcohol use, and sexual risk taking. Reconsideration appears to represent a way of changing course in early and middle adolescence, but it may be accompanied by some negative consequences.

The present findings further suggest that chronic reconsideration, repeated shifting of commitments, and/or elevated degrees of depression or anxiety may suggest an underlying problem with the beginnings of self-organization in early adolescence. Campbell (1990, Campbell et al. 1996, 2003) define self-concept clarity using a number of criteria, including coherence among one's various roles and commitments and possessing the ability and confidence to communicate one's sense of self to other people. Further, Heath and Brown (1999) found that, when children and young adolescents are not able to integrate their various aspects of self (e.g., academic, social, athletic) into a coherent whole, they are more likely to report depressive symptoms. Indeed, the present findings are consistent with Erikson's (1950) conceptualization of identity synthesis versus confusion. Especially in Western societies where adult commitments are enacted in the mid-twenties, purposeful identity work must begin in adolescence-even if the sense of self is not consolidated until later on (cf. Crocetti et al. 2010). Establishing a clear sense of self, as well as the confidence and desire to express this self to others, is therefore an essential task of early and middle adolescence. It is likely, of course, that later events-such as leaving the parental home, starting college, and entering into long-term romantic relationships-will require further reconfiguration and adjustment within one's self-concept. Such transitions, then, may trigger periods of reconsideration, exploration, and perhaps rumination and distress. And although some distress is normative during periods of reconsideration and exploration (Crocetti et al. 2008b; Schwartz et al. 2009b), elevated symptoms of depression and anxiety may serve as a signal that some sort of intervention is needed.

The present results also suggest that the self-system may provide important information regarding antecedents of anxiety and depressive symptoms in early and middle adolescence. Specifically, the relatively small proportion of adolescents reporting elevated levels of anxiety and depressive symptoms (Garber et al. 2002; Hale et al. 2008) may experience elevated confusion and uncertainty regarding their sense of self and their identity commitments. Arnett (1999) notes that a fairly small percentage of adolescents experience identity problems - and the present results suggest that these may be the same adolescents who report heightened levels of internalizing symptoms. Helping adolescents to develop a coherent and integrated selfsystem may represent an important way to prevent or decrease internalizing problems.

On a more theoretical level, the present findings suggest that self-concept and identity are complementary, but still somewhat distinct from one another. Commitment and reconsideration may represent how the self-concept is formed and revised, and self-concept clarity may serve as an index of how well or poorly the identity development process is proceeding. As suggested in the introductory section, making commitments does not necessarily guarantee that these commitments will be compatible with one another, but it does appear that maintaining strong commitments helps to maximize the likelihood that these commitments fit well with each other. Moreover, as suggested earlier, reconsideration appears to represent the process through which self-concept and identity are revised. Again, however, it should be noted that identity was assessed only within the educational and friendship domains, whereas self-concept clarity was assessed as a general process. Nevertheless, the present study does provide a strong foundation for further research on the structure and functions of the self-system in adolescence.

\section{Limitations}

The present results should be interpreted in light of some important limitations. First, all data were self-reported by the adolescent. When scores for all constructs are obtained from the same source, shared method variance may inflate the relationships among variables (Podsakoff et al. 2003). More in-depth clinical interviews may help to clarify the specific depressive or anxiety symptoms that the adolescent is experiencing.

Second, we measured identity only in two domainseducation and best friend. Although prior research suggests that these domains provide some degree of breadth in terms of the areas in which identity work is occurring (e.g., Crocetti et al. 2010), a wider array of domains might have provided a more accurate portrayal of adolescents' identity development. Erikson (1950, 1968) and Marcia (e.g., Kroger and Marcia 2011) have enumerated a number of identity domains, including career, religion, values, gender roles, and political beliefs. Although many of these 
domains may not be relevant for early adolescents, it may be possible to construct items referring to domains that are salient for this age period-such as family relationships, body image, and popularity. Creating and validating such items is important for future research.

Third, although the present study was longitudinal, adolescents were not followed into the emerging adult years, when identity tends to be consolidated (Schwartz 2007). Indeed, Schwartz (2005) has called for studies to follow individuals from early adolescence through the entry into adult roles, so that we can understand how identity work begins and continues through the enactment of adult commitments.

Fourth, the vast majority of the adolescents in the present sample were of White Dutch ethnicity. Relatively few adolescents were from minority backgrounds. As a result, sample size issues precluded examination of the consistency of our findings across ethnicity. In future work, it may be important to oversample from ethnic minority groups so that cross-ethnic comparisons can be conducted.

Fifth, given that the present study focused only on adolescents' self-reported internalizing symptoms (i.e. depressive and anxiety symptoms), the results cannot be readily extrapolated to adolescents from clinical populations. However, referral bias in adolescent clinical populations may limit generalizability-and we argue that prospective, community studies of adolescents may better characterize the course of adolescent disorders (Hale et al. 2005). Additionally, as noted by Hale et al. (2010), longitudinal community samples allow for the exploration of the development of adolescent internalizing symptoms, such as anxiety symptoms, before they have reached clinically significant severity.

\section{Conclusion}

Despite the above and other limitations, the present study has provided a strong base for continued work on the interplay of self and identity processes in early to middle adolescents-as well as the consequences of this interplay for psychosocial functioning. Although the overlap between self-concept and identity has been debated in the literature (e.g., Côté and Levine 2002; Roeser et al. 2006; Vignoles et al. 2011), the present study is among the first empirical examinations of the associations among these constructs-as well as their relationships to internalizing problems. A well-functioning self-system, consisting of commitments that one has made within life domains such as peer relationships, education, physical attractiveness, and athletic competence is likely to contraindicate the development of internalizing problems-whereas a confused or poorly integrated self-system represents a risk for internalizing problems. We hope that the present findings will find their way into practice settings, where they can be used to help young people develop a sense of identity and self-concept clarity and to prevent escalations in depressive and anxiety symptoms. We also hope that the present study will inspire more empirical work integrating the self and identity literatures. It is through such integrative work that developmental science can be advanced most successfully.

\section{References}

Arnett, J. J. (1999). Adolescent storm and stress, reconsidered. American Psychologist, 54, 317-326.

Berzonsky, M. D. (2003). Identity style and well-being: Does commitment matter? Identity: An International Journal of Theory and Research, 3, 131-142.

Berzonsky, M. D., \& Kinney, A. (2008). Identity processing style and defense mechanisms. Polish Psychological Bulletin, 39, 111-117.

Birmaher, B., Khetarpal, S., Brent, D., \& Cully, M. (1997). The Screen for Child Anxiety Related Emotional Disorders (SCARED): Scale construction and psychometric characteristics. Journal of the American Academy of Child and Adolescent Psychiatry, 36, 545-553.

Bosma, H. A., \& Kunnen, E. (2001). Determinants and mechanisms in ego identity development: A review and synthesis. Developmental Review, 21, 39-66.

Bouchey, H. A., \& Harter, S. (2005). Reflected appraisals, academic self-perceptions, and math/science performance during early adolescence. Journal of Educational Psychology, 97, 673-686.

Branje, S. J. T., Frijns, T., Finkenauer, C., Engels, R., \& Meeus, W. (2007). You are my best friend: Commitment and stability in adolescents' same-sex friendships. Personal Relationships, 14, 587-603.

Brubaker, R., \& Cooper, F. (2000). Beyond "identity". Theory and Society, 29, 1-47.

Byrne, B. M. (2011). Structural equation modeling with Mplus: Basic concepts, applications, and programming. Philadelphia, PA: Taylor and Francis.

Campbell, J. D. (1990). Self-esteem and clarity of the self-concept. Journal of Personality and Social Psychology, 59, 538-549.

Campbell, J. D., Assanand, S., \& Di Paula, A. (2003). The structure of the self-concept and its relation to psychological adjustment. Journal of Personality, 71, 115-140.

Campbell, J. D., Trapnell, P. D., Heine, S. J., Katz, I. M., Lavallee, L. F., \& Lehman, D. R. (1996). Self-concept clarity: Measurement, personality correlates, and cultural boundaries. Journal of Personality and Social Psychology, 70, 141-156.

Chen, F. F. (2007). Sensitivity of goodness of fit indexes to lack of measurement invariance. Structural Equation Modeling, 14, 464-504.

Cohen, J. (1988). Statistical power analysis for the behavioral sciences. Hillsdale, NJ: Lawrence Erlbaum Associates.

Constantino, M. J., Wilson, K. R., Horowitz, L. M., \& Pinel, E. C. (2006). The direct and stress-buffering effects of self-organization on psychological adjustment. Journal of Social and Clinical Psychology, 25, 333-360.

Côté, J. E., \& Levine, C. G. (2002). Identity formation, agency, and culture: A social psychological synthesis. Mahwah, NJ: Lawrence Erlbaum Associates.

Craighead, W., Smucker, M. R., Craighead, L., \& Ilardi, S. S. (1998). Factor analysis of the Children's Depression Inventory in a community sample. Psychological Assessment, 10, 156-165. 
Crocetti, E., Klimastra, T. A., Keijsers, L., Hale, W. W., \& Meeus, W. (2009). Anxiety trajectories and identity development in adolescence: A five-wave longitudinal study. Journal of Youth and Adolescence, 38, 839-849.

Crocetti, E., Rubini, M., Luyckx, K., \& Meeus, W. (2008a). Identity formation in early and middle adolescents from various ethnic groups: From three dimensions to five statuses. Journal of Youth and Adolescence, 37, 983-996.

Crocetti, E., Rubini, M., \& Meeus, W. (2008b). Capturing the dynamics of identity formation in various ethnic groups: Development and validation of a three-dimensional model. Journal of Adolescence, 31, 207-222.

Crocetti, E., Schwartz, S. J., Fermani, A., \& Meeus, W. (2010). The Utrecht-Management of Identity Commitments Scale (U-MICS): Italian validation and cross-national comparisons. European Journal of Psychological Assessment, 26, 172-186.

Davey, A., \& Savla, J. (2010). Statistical power analysis with missing data: A structural equation modeling approach. New York: Routledge.

Dimitrov, D. M. (2010). Testing for factorial invariance in the context of construct validation. Measurement and Evaluation in Counseling and Development, 43, 121-149.

Dishman, R. K., Hales, D. P., Pfeiffer, K. A., Felton, G. A., Saunders, R., Ward, D. S., et al. (2006). Physical self-concept and selfesteem mediate cross-sectional relations of physical activity and sport participation with depression symptoms among adolescent girls. Health Psychology, 25, 396-407.

Duncan, T. E., Duncan, S. C., Strycker, L. A., Li, F., \& Alpert, A. (1999). An introduction to latent variable growth curve modeling: Concepts, issues, and applications. Mahwah, NJ: Lawrence Erlbaum Associates.

Erikson, E. H. (1950). Childhood and society. New York: Norton.

Erikson, E. H. (1968). Identity: Youth and crisis. New York: Norton.

Garber, J., Keiley, M. K., \& Martin, N. (2002). Developmental trajectories of adolescents' depressive symptoms: Predictors of change. Journal of Consulting and Clinical Psychology, 70, 79-95.

Giulietti, M., Otero, J., \& Smith, J. (2009). Testing for stationarity in heterogeneous panel data in the presence of cross-section dependence. Journal of Statistical Computation and Simulation, 79, 195-203.

Grotevant, H. D. (1987). Toward a process model of identity formation. Journal of Adolescent Research, 2, 203-222.

Guay, F., Larose, S., \& Boivin, M. (2004). Academic self-concept and educational attainment level: A ten-year longitudinal study. Self and Identity, 3, 53-68.

Hale, W. W., III, Crocetti, E., Raaijmakers, Q., \& Meeus, W. (2011). A meta-analysis of the cross-cultural psychometric properties of the Screen for Child Anxiety Related Emotional Disorders (SCARED). Journal of Child Psychology and Psychiatry, 52, 80-90.

Hale, W. W., III, Klimstra, T. A., \& Meeus, W. (2010). Is the Generalized Anxiety Disorder symptom of worry just another form of neuroticism? A five-year longitudinal study of adolescents from the general population. Journal of Clinical Psychiatry, 71, 942-948.

Hale, W. W., III, Raaijmakers, Q., Muris, P., \& Meeus, W. (2005). Psychometric properties of the Screen for Child Anxiety Related Emotional Disorders (SCARED) in the general adolescent population. Journal of the American Academy of Child and Adolescent Psychiatry, 44, 283-290.

Hale, W. W., III, Raaijmakers, Q., Muris, P., van Hoof, A., \& Meeus, W. (2008). Developmental trajectories of adolescent anxiety disorder symptoms: A 5-year prospective community study. Journal of the American Academy of Child and Adolescent Psychiatry, 47, 556-564.
Hancock, G. R., \& Freeman, M. J. (2001). Power and sample size for the root mean square error of approximation test of not close fit in structural equation modeling. Educational and Psychological Measurement, 61, 741-758.

Hankin, B. L., \& Abramson, L. Y. (2001). Development of gender differences in depression: An elaborated cognitive vulnerabilitytransactional stress theory. Psychological Bulletin, 127, 773796.

Harter, S. (1999). The construction of the self: A developmental perspective. New York: Guilford.

Heath, N., \& Brown, A. E. (1999). Self-concept differentiation and depressive symptomatology in children. International Journal of Psychology, 34, 95-105.

Hodges, K. (1990). Depression and anxiety in children: A comparison of self-report questionnaires to clinical interviews. Psychological Assessment, 2, 376-381.

Keith, T. Z. (2006). Multiple regression and beyond. Boston: Allyn and Bacon.

Klimstra, T. A., Akse, J., Hale, W. W., III, Raaijmakers, Q. A. W., \& Meeus, W. H. J. (2010a). Longitudinal associations between personality traits and problem behavior symptoms in adolescence. Journal of Research in Personality, 44, 273-284.

Klimstra, T. A., Hale, W. W., III, Raijmakers, Q. A. W., Branje, S. J. T., \& Meeus, W. H. J. (2010b). Identity formation in adolescence: Change or stability? Journal of Youth and Adolescence, 39, 150-162.

Klimstra, T. A., Luyckx, K., Hale, W. W., III, Frijns, T., van Lier, P. A. C., \& Meeus, W. H. J. (2010c). Short-term fluctuations in identity: Introducing a micro-level approach to identity formation. Journal of Personality and Social Psychology, 99, 191-202.

Kline, R. B. (2006). Principles and practices of structural equation modeling (2nd ed.). New York: Guilford.

Kovacs, M. (1985). The Children's Depression Inventory. Psychopharmacology Bulletin, 21, 995-998.

Kroger, J., \& Marcia, J. E. (2011). The identity statuses: Origins and interpretations. In S. J. Schwartz, K. Luyckx, \& V. L. Vignoles (Eds.), Handbook of identity theory and research (pp. 31-54). New York: Springer.

Leary, M. R. (2004). Editorial: What is the self: A plea for clarity. Self and Identity, 3, 1-3.

Lewis, H. L. (2003). Differences in ego identity among college students across age, ethnicity, and gender. Identity: An International Journal of Theory and Research, 3, 159-189.

Little, R. J. A. (1988). A test of missing completely at random for multivariate data with missing values. Journal of the American Statistical Association, 83, 1198-1202.

Locke, K. D. (2006). What predicts well-being? A consistent selfconcept or a desirable self-concept? Journal of Social and Clinical Psychology, 25, 228-247.

Luyckx, K., Goossens, L., Soenens, B., \& Beyers, W. (2006). Unpacking commitment and exploration: Preliminary validation of an integrative model of late adolescent identity formation. Journal of Adolescence, 29, 361-378.

Luyckx, K., Goossens, L., Soenens, B., Beyers, W., \& Vansteenkiste, M. (2005). Identity statuses based on 4 rather than 2 identity dimensions: Extending and refining Marcia's paradigm. Journal of Youth and Adolescence, 34, 605-618.

Luyckx, K., Schwartz, S. J., Berzonsky, M. D., Soenens, B., Vansteenkiste, M., Smits, I., et al. (2008a). Capturing ruminative exploration: Extending the four-dimensional model of identity formation in late adolescence. Journal of Research in Personality, 42, 58-82.

Luyckx, K., Schwartz, S. J., Goossens, L., \& Pollock, S. (2008b). Employment, sense of coherence, and identity formation: Contextual and psychological processes on the pathway to sense of adulthood. Journal of Adolescent Research, 23, 566-591. 
Luyckx, K., Schwartz, S. J., Goossens, L., \& Soenens, B. (2008c). Developmental typologies of identity formation and adjustment in female emerging adults: A latent class growth analysis approach. Journal of Research on Adolescence, 18, 595-619.

Luyckx, K., Soenens, B., Goossens, L., Beckx, K., \& Wouters, S. (2008d). Identity exploration and commitment in late adolescence: Correlates of perfectionism and mediating mechanisms on the pathway to well-being. Journal of Social and Clinical Psychology, 27, 336-361.

Marcia, J. E. (1966). Development and validation of ego identity status. Journal of Personality and Social Psychology, 3, 551-558.

Marcia, J. E. (1980). Identity in adolescence. In J. Adelson (Ed.), Handbook of adolescent psychology (pp. 159-187). New York: Wiley.

Marcia, J. E. (1993). The ego identity status approach to ego identity. In J. E. Marcia, A. S. Waterman, D. R. Matteson, S. L. Archer, \& J. L. Orlofsky (Eds.), Ego identity: A handbook for psychosocial research (pp. 1-21). New York: Springer-Verlag.

Meeus, W. (1996). Studies on identity development in adolescence: An overview of research and some new data. Journal of Youth and Adolescence, 25, 569-598.

Meeus, W. (2011). The study of adolescent identity formation 2000-2010. A review of longitudinal research. Journal of Research on Adolescence, 21, 75-94.

Meeus, W., Akse, J., Branje, S., Ter Bogt, T., Delsing, M., Van Doorn, M., et al. (2004). Codebook CONAMORE: COnflicts and Management of RElationships. Utrecht, The Netherlands: Research Centre on Adolescent Development.

Meeus, W., Iedema, J. J., Helsen, M. M., \& Vollebergh, W. W. (1999). Patterns of adolescent identity development: Review of literature and longitudinal analysis. Developmental Review, 19(4), 419-461.

Meeus, W., van de Schoot, R., Keijsers, L., Schwartz, S. J., \& Branje, S. (2010). On the progression and stability of adolescent identity formation: A five-wave longitudinal study in early-to-middle and middle-to-late adolescence. Child Development, 81, 1565-1581.

Montague, M., Enders, C., Dietz, S., Dixon, J., \& Cavendish, W. (2008). A longitudinal study of depressive symptomatology and self-concept in adolescents. Journal of Special Education, 42, 67-78.

Muris, P., Merckelbach, H., Van Brakel, A., \& Mayer, B. (1999). The revised version of the Screen for Child Anxiety Related Emotional Disorders (SCARED-R): Further evidence for its reliability and validity. Anxiety, Stress, and Coping: An International Journal, 12, 411-425.

Muris, P., \& Steerneman, P. (2001). The revised version of the Screen for Child Anxiety Related Emotional Disorders (SCARED-R): First evidence for its reliability and validity in a clinical sample. British Journal of Clinical Psychology, 40, 35-44.

Muthén, L. K., \& Muthén, B. O. (2007). Mplus user's guide, version 5. Los Angeles: Muthén and Muthén.

Podsakoff, P. M., MacKenzie, S. B., Lee, J., \& Podsakoff, N. P. (2003). Common method biases in behavioral research: A critical review of the literature and recommended remedies. Journal of Applied Psychology, 88, 879-903.

Porfeli, E. J., \& Skorikov, V. B. (2010). Specific and diverse career exploration during late adolescence. Journal of Career Assessment, 18, 46-58.

Robles-Piña, R. A., Defrance, E., \& Cox, D. (2008). Self-concept, early childhood depression and school retention as predictors of adolescent depression in urban Hispanic adolescents. School Psychology International, 29, 426-441.

Roeser, R. W., Peck, S. C., \& Nasir, N. (2006). Self and identity processes in school motivation, learning, and achievement. In P. A. Alexander \& P. H. Winne (Eds.), Handbook of educational psychology (pp. 391-424). Mahwah, NJ: Lawrence Erlbaum Associates.

Schwartz, S. J. (2005). A new identity for identity research: Recommendations for expanding and refocusing the identity literature. Journal of Adolescent Research, 20, 293-308.

Schwartz, S. J. (2007). The structure of identity consolidation: Multiple correlated constructs or one superordinate construct? Identity: An International Journal of Theory and Research, 7, 27-49.

Schwartz, S. J., Beyers, W., Luyckx, K., Soenens, B., Zamboanga, B. L., Forthun, L. F., et al. (2011a). Examining the light and dark sides of emerging adults' identity: A study of identity status differences in positive and negative psychosocial functioning. Journal of Youth and Adolescence, 40, 839-859.

Schwartz, S. J., Donnellan, M. B., Ravert. R. D., Luyckx, K., \& Zamboanga, B. L. (in press). Identity development, personality, and well-being in adolescence and emerging adulthood: Theory, research, and recent advances. In I. B. Weiner (Series Ed.), and R. M. Lerner, A. Easterbrooks, \& J. Mistry (Vol. Eds.), Handbook of psychology, vol. 6: Developmental psychology. New York: Wiley.

Schwartz, S. J., Klimstra, T. A., Luyckx, K., Hale, W. W., I. I. I., Frijns, T., Oosterwegel, A., et al. (2011b). Daily dynamics of personal identity and self-concept clarity. European Journal of Personality, 25, 373-385.

Schwartz, S. J., Mason, C. A., Pantin, H., \& Szapocznik, J. (2009a). Longitudinal relationships between family functioning and identity development in Hispanic immigrant adolescents: Continuity and change. Journal of Early Adolescence, 29, 177-211.

Schwartz, S. J., \& Montgomery, M. J. (2002). Similarities or differences in identity development? The impact of acculturation and gender on identity process and outcomes. Journal of Youth and Adolescence, 31, 359-372.

Schwartz, S. J., Pantin, H., Prado, G., Sullivan, S., \& Szapocznik, J. (2005). Family functioning, identity, and problem behavior in Hispanic immigrant early adolescents. Journal of Early Adolescence, $25,392-420$.

Schwartz, S. J., Zamboanga, B. L., Weisskirch, R. S., \& Rodriguez, L. (2009b). The relationships of personal and ethnic identity exploration to indices of adaptive and maladaptive psychosocial functioning. International Journal of Behavioral Development, 33, 131-144.

Schwartz, S. J., Zamboanga, B. L., Wang, W., \& Olthuis, J. V. (2009c). Measuring identity from an Eriksonian perspective: Two sides of the same coin? Journal of Personality Assessment, 91, 143-154.

Serafini, T. E., \& Adams, G. R. (2002). Functions of identity: Scale construction and validation. Identity: An International Journal of Theory and Research, 2, 361-389.

Slutzky, C. B., \& Simpkins, S. D. (2009). The link between children's sport participation and self-esteem: Exploring the mediating role of sport self-concept. Psychology of Sport and Exercise, 10, 381-389.

Smits, I., Soenens, B., Vansteenkiste, M., Luyckx, K., \& Goossens, L. (2010). Why do adolescents gather information or stick to parental norms? Examining autonomous and controlled motives behind adolescents' identity style. Journal of Youth and Adolescence, 39, 1343-1356.

Stopa, L., Brown, M. A., Luke, M. A., \& Hirsch, C. R. (2010). Constructing a self: The role of self-structure and self-certainty in social anxiety. Behavior Research and Therapy, 48, 955-965.

van Oort, F. V. A., Greaves-Lord, K., Verhulst, F. C., Ormel, J., \& Huizink, A. C. (2009). The developmental course of anxiety symptoms during adolescence: The TRAILS study. Journal of Child Psychology and Psychiatry, 50, 1209-1217. 
Vignoles, V. L., Schwartz, S. J., \& Luyckx, K. (2011). Introduction: Toward an integrative view of identity. In S. J. Schwartz, K. Luyckx, \& V. L. Vignoles (Eds.), Handbook of identity theory and research (pp. 1-28). New York: Springer.

Waterman, A. S. (1999). Identity, the identity statuses, and identity status development: A contemporary statement. Developmental Review, 19, 591-621.

Waterman, A. S. (2004). Finding someone to be: Studies on the role of intrinsic motivation in identity formation. Identity: An International Journal of Theory and Research, 4, 209-228.

Waterman, A. S. (2007). Doing well: The relationship of identity status to three conceptions of well-being. Identity: An International Journal of Theory and Research, 7, 289-307.

Weston, R., \& Gore, P. R. (2006). A brief guide to structural equation modeling. Counseling Psychologist, 34, 719-751.

Wickrama, T., \& Wickrama, K. S. (2010). Heterogeneity in adolescent depressive symptom trajectories: Implications for young adults' risky lifestyle. Journal of Adolescent Health, 47, 407-413.

\section{Author Biographies}

Seth J. Schwartz is an Associate Professor in the Department of Epidemiology and Public Health, Leonard M. Miller School of Medicine, University of Miami. His research interests include identity (broadly defined), well-being, ethnicity and culture, positive youth development, and drug abuse and HIV prevention.
Theo A. Klimstra is a Post-Doctoral Scholar in the Department of Psychology, Catholic University of Leuven, Belgium. His research interests include identity and personality development in adolescence, as well as innovative ways of studying developmental change.

Koen Luyckx is a Research Professor in the Department of Psychology, Catholic University of Leuven, Belgium. His research interests include personal identity processes; the transition to adulthood; parenting, parent-adolescent conflict, and parent-adolescent relationships; psychosocial adaptation to being afflicted with a chronic illness; coping; burn-out and engagement at the workfloor; and long-term development of biopsychosocial indices and interdependencies across childhood and adolescence.

William W. Hale III is Assistant Professor at the Research Centre Adolescent Development, Utrecht University. He received his Ph.D. at the Department of Biological Psychiatry, University of Groningen, The Netherlands. His research interests include the development and measurement of anxiety and depression in adolescence.

Wim H. J. Meeus is Professor of Adolescent Development and Chair of the Research Centre on Adolescent Development of Utrecht University. He received his Ph.D. in Social Psychology from the Utrecht University. His research interests include identity development, the development of friendships in adolescence, parenting processes in families of adolescents, and adolescent anxiety and depression. 